\title{
Complexes of Silver with Histidine and Imidazole Investigated by the Calorimetric and Potentiometric Methods
}

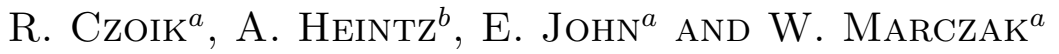 \\ ${ }^{a}$ Institute of Chemistry, University of Silesia, Szkolna 9, 40-006 Katowice, Poland \\ ${ }^{b}$ Department of Physical Chemistry, University of Rostock \\ Hermannstr. 14, D-18051 Rostock, Germany
}

\begin{abstract}
The stability constants and enthalpies of formation of silver (I) complexes with histidine and imidazole were determined. Two types of complexes were found: $\mathrm{AgL}^{+}$and $\mathrm{AgL}_{2}^{+}$. The second is much more stable that is evidenced by the higher stability constants and enthalpies of formation. For the two systems, the respective constants and enthalpies are very close one to another that suggests similar complexation mechanisms. Most probably, the linear complexes through the N-3 pyridinic atoms are being formed. The calorimetric and potentiometric methods gave virtually the same results for the system silver + imidazole. However, the potentiometric method failed for the histidine system. The molecule of histidine has three protonation spots, two of these probably do not take part in the complexation but their protonation equilibria may shift upon joining the ions of silver and influence the $\mathrm{pH}$ of the system in that way.
\end{abstract}

PACS numbers: $82.60 . \mathrm{Hc}$

\section{Introduction}

Beneficial healing and anti-disease properties of silver have been known already to Hippocrates. Silver ions and silver compounds are toxic to some bacteria, viruses, algae and fungi. For that reason, silver-based medicines have been widely used for centuries. Contrary to other heavy metals, silver is harmless to humans, although it may cause argyria when used excessively. After discovery of antibiotics, the use of silver and its compounds as germicides decreased. However, the interest in silver as an anti-microbial has been renewed in the last years. For example, Samsung introduced a series of home electronic appliances equipped with the so-called Silver Nano Health System three years ago. A coating of silver ions applied to inner walls of refrigerators, the filters of air conditioners and vacuum cleaners inhibits the growth of bacteria and fungi. 
Histidine (Fig. 1) belongs to the group of 20 natural amino acids present in proteins. It can act as a catalytic site in certain enzymes and as a coordinating ligand in metalloproteins. The affinity of histidine for metal ions can be used e.g. in quantitative chemical analysis or synthesis of medicines. In spite of the prominent role played by histidine in biochemical reactions, the complexes of silver with histidine were studied rather scarcely and the results seemed ambiguous [1]. To the best of our knowledge, the complexing enthalpies have never been reported. Although the information about the complexes with imidazole might seem ample $[1,2]$, only one set of enthalpies measured directly is available [3].

\section{Experimental results}

The calorimetric experiment was performed using a 2277 Thermal Activity Monitor (Thermometric, Sweden) equipped with a $4 \mathrm{~cm}^{3}$ titration cell. Aqueous solution of silver nitrate, $c=0.2 \mathrm{~mol} \mathrm{dm}^{-3}$, was injected in drops of $12 \mathrm{~mm}^{3}$ volume into the titration cell filled with $2.8 \mathrm{~cm}^{3}$ of the aqueous ligand solution, $c=0.02 \mathrm{~mol} \mathrm{dm}^{-3}$. In order to determine the heats of dilution, the silver nitrate was titrated to water, and water to the ligand solutions. The heat effect of the first process was big enough to be taken into account in the calculations, while that of the second one was negligible. Before the measurements, the apparatus was checked on the basis of chemical test - the enthalpies of binding of $\mathrm{Ba}^{2+}$ ions to 18-crown-6 ether were found slightly higher than the values reported in the literature, by approximately $0.5 \%[4]$ and $1.5 \%[5,6]$. These differences lie within the limits of the measurement accuracy.
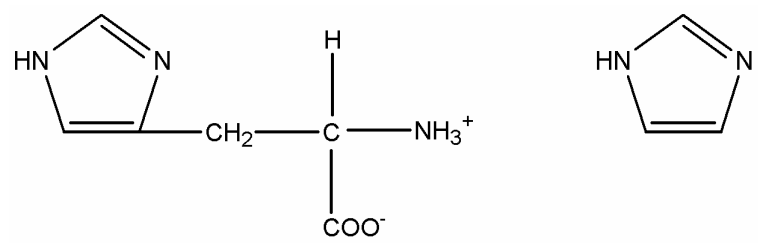

Fig. 1. The molecules of histidine (left) and imidazole (right).

Two independent calorimetric titrations were made for each of the two systems at temperature $298.15 \mathrm{~K}$. A model with two consecutive complexing reactions

$$
\begin{aligned}
& \mathrm{Ag}^{+}+\mathrm{L}=\mathrm{AgL}^{+}, \\
& \mathrm{AgL}^{+}+\mathrm{L}=\mathrm{AgL}_{2}^{+},
\end{aligned}
$$

where L stands for histidine or imidazole, satisfactorily approximated the empirical results. The enthalpies and equilibrium constants of the reactions (1) and (2) were calculated from the four datasets, each obtained in single experimental run, using the software supplied with the calorimeter by Thermometric. Since the results for a particular system were found approximately the same, the model was fitted again to two combined datasets: one set for the system with imidazole and the 
other for that with histidine. The experimental data and fitted curves are plotted in Fig. 2, while the equilibrium constants, $K_{i}$ and $\beta_{2}=K_{1} K_{2}$, are reported in Table I, and enthalpies, $\Delta H_{i}$, in Table II. The constants at temperature $293.15 \mathrm{~K}$ were calculated from the van't Hoff isobar

$$
\left(\delta \ln K_{i} / \delta T\right)_{p}=\Delta H_{i} / R T^{2}
$$

where $i$ denotes reaction (1) or (2), $R$ is the universal gas constant, $T$ and $p$ are temperature and pressure, respectively.
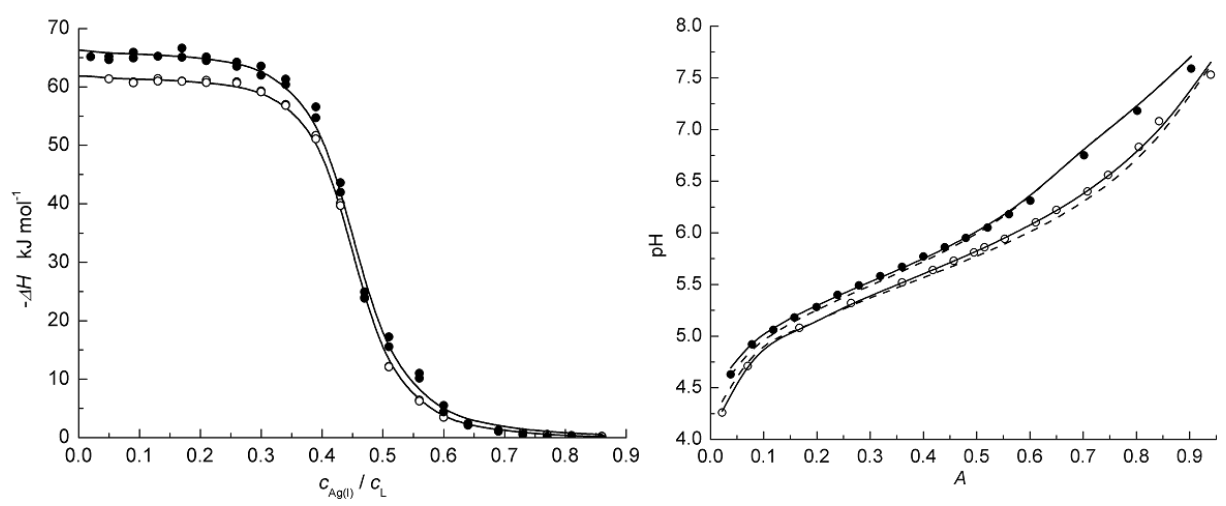

Fig. 2. The titration curves. Calorimetric experiment (left): the heat effects of the complexing of silver (I) by histidine (o) and imidazole $(\bullet)$ at $298.15 \mathrm{~K}$; points - experimental results, lines - fitted model. Potentiometric experiment (right): the fraction titrated, $A=n_{\mathrm{KOH}} / n_{\mathrm{L}}$, vs. $\mathrm{pH}$ of the system silver + imidazole at $293.15 \mathrm{~K}$; points - experimental results for the molar ratios $n_{\mathrm{Ag}+}: n_{\mathrm{Im}}=1: 2.5$ (०) and $n_{\mathrm{Ag}+}: n_{\mathrm{Im}}=$ $1: 3.3(\bullet)$, solid lines — fitted model, dashed lines — calculated with the complexation constants obtained by the calorimetric method.

The potentiometric experiment was based on changes in the concentration of hydrogen ions released during the complexation. The solution of $\mathrm{KOH}, c=$ $0.2 \mathrm{~mol} \mathrm{dm}^{-3}$, was titrated into the mixture containing histidine or imidazole, silver nitrate and $\mathrm{HNO}_{3}$. Several measurements were made for concentrations of the $\operatorname{Ag}(\mathrm{I})$ ions from 1 to $8 \mathrm{mmol} \mathrm{dm}{ }^{-3}$ and of the ligands from 10 to $25 \mathrm{mmol}$ $\mathrm{dm}^{-3}$. The concentration ratio of silver to ligands ranged from 1:2 to 1:6, and $\mathrm{HNO}_{3}$ was added in the amounts sufficient for complete protonation of the ligands. The solvent for the titrant and the analytes was aqueous $\mathrm{KNO}_{3}, c=0.1 \mathrm{~mol}$ $\mathrm{dm}^{-3}$, to provide constant ionic strength. Changes of $\mathrm{pH}$ during the titration were determined using a Radiometer PHM-220 pH-meter equipped with the glass and calomel electrodes. The measuring set was calibrated using standard buffer solutions.

The potentiometric titrations gave similar results as the calorimetric ones for the system silver + imidazole at 293.15 K. Again, several sets of the equilibrium constants for the reactions (1) and (2) were obtained by fitting the model to the 
TABLE I

Stability constants of the complexes of silver (I) with imidazole and histidine (cf. Eqs. (1) and (2), determined in this work and reported in the literature. $K_{i}$ in $\left[\mathrm{dm}^{-3} \mathrm{~mol}\right], \beta_{2}$ in $\left[\mathrm{dm}^{-6} \mathrm{~mol}^{2}\right]$.

\begin{tabular}{c|c|c|c|c|c|c}
\hline \hline $\log \left(K_{1}\right)$ & $\log \left(K_{2}\right)$ & $\log \left(\beta_{2}\right)$ & Method $^{a}$ & $\mathrm{pH}$ & $t\left[{ }^{\circ} \mathrm{C}\right]$ & Reference \\
\hline \multicolumn{6}{c}{$\mathrm{Ag}+$ imidazole } \\
\hline $2.96 \pm 0.15$ & 3.75 & $6.71 \pm 0.07$ & calorim. & $6.3-8.9$ & 25 & this work \\
$2.92 \pm 0.05$ & $3.79 \pm 0.05$ & $6.71 \pm 0.05$ & & & 25 & {$[2] b$} \\
3.16 & 4.00 & 7.16 & calorim. & $6.3-8.9$ & 20 & this work \\
$3.33 \pm 0.15^{c}$ & $3.79 \pm 0.08^{c}$ & $7.12 \pm 0.08^{c}$ & glass & $2-8.5$ & & \\
3.24 & 3.89 & 7.13 & glass & & 20 & {$[7]$} \\
\hline \multicolumn{7}{c}{$\mathrm{Ag}+$ histidine } \\
\hline $2.85 \pm 0.04$ & 3.89 & $6.74 \pm 0.01$ & calorim. & $5.3-7.3$ & 25 & this work \\
$2.30 \pm 0.22^{d}$ & $0.75 \pm 0.19^{d}$ & $3.05^{d}$ & glass & $c a .7$ & 25 & {$[9]$} \\
$6.93 \pm 0.19^{e}$ & $3.24 \pm 0.16^{e}$ & $10.17^{e}$ & glass & $c a .9$ & 25 & \\
6.45 & 3.02 & glass & & 25 & {$[10]$} \\
5.42 & 8.44 & glass & & 30 & {$[11]$} \\
\hline
\end{tabular}

${ }^{a}$ methods: calorim. - calorimetric; glass - potentiometric with glass electrode; ISE — potentiometric with ion selective electrode;

${ }^{b}$ recommended by IUPAC for the ionic strength $I=0$;

${ }^{c}$ mean value and range for three datasets;

${ }^{d}$ complexes with protonated ligands: $[\mathrm{Ag}(\mathrm{HL})]^{+},\left[\mathrm{Ag}(\mathrm{HL})_{2}\right]^{+}$;

${ }^{e}$ complexes with deprotonated ligands: $[\mathrm{AgL}]$ and $\left[\mathrm{AgL}_{2}\right]^{-}$

TABLE II

Enthalpies of complexing of silver (I) by the imidazole and histidine ligands (cf. Eqs. (1) and (2)); the values measured calorimetrically (this work and Ref. [3]) and calculated from the results of a potentiometric experiment [7].

\begin{tabular}{|c|c|c|c|c|c|}
\hline \multirow[t]{2}{*}{ Ligand } & $-\Delta H_{1}$ & $-\Delta H_{2}$ & $-\left(\Delta H_{1}+\Delta H_{2}\right)$ & \multirow[t]{2}{*}{$t\left[{ }^{\circ} \mathrm{C}\right]$} & \multirow[t]{2}{*}{ Reference } \\
\hline & \multicolumn{3}{|c|}{$\left[\mathrm{kJ} \mathrm{mol}^{-1}\right]$} & & \\
\hline \multirow[t]{3}{*}{ imidazole } & $29.4 \pm 1.0$ & 36.9 & $66.3 \pm 0.4$ & 25 & this work \\
\hline & 30.5 & 35.1 & 65.6 & 25 & {$[3]^{a}$} \\
\hline & 23 & 43 & 66 & 20 & {$[1,7]$} \\
\hline histidine & $24.7 \pm 0.3$ & 37.2 & $61.8 \pm 0.1$ & 25 & this work \\
\hline
\end{tabular}

experimental data. To this end, a computer program [12] was used. Examples of the titration curves are given in Fig. 2. The average values of the equilibrium 
constants are reported in Table I. Unfortunately, the model given by reactions (1) and (2) could not account for the changes of $\mathrm{pH}$ in the potentiometric titrations of the system silver + histidine. Although several other models have been tried too, no satisfactory result has been obtained. Thus, we decided to postpone further attempts until another experiment with an ion selective electrode is complete.

\section{Conclusions}

The imidazole ligands form two complex compounds with the $\mathrm{Ag}(\mathrm{I})$ ions: $\operatorname{Ag}\left[\mathrm{C}_{3} \mathrm{~N}_{2} \mathrm{H}_{4}\right]^{+}$and $\mathrm{Ag}\left[\mathrm{C}_{3} \mathrm{~N}_{2} \mathrm{H}_{4}\right]_{2}^{+}$. The latter form is much more stable that is illustrated by the distribution diagrams plotted in Fig. 3. Similar complexes are most probably formed by histidine as well, at least in the neutral and slightly acidic solutions. This conclusion is supported by approximately the same enthalpies and stability constants for the two systems. Consequently, the respective distribution curves look alike (Fig. 3). Moreover, the ion selective electrode experiment re-

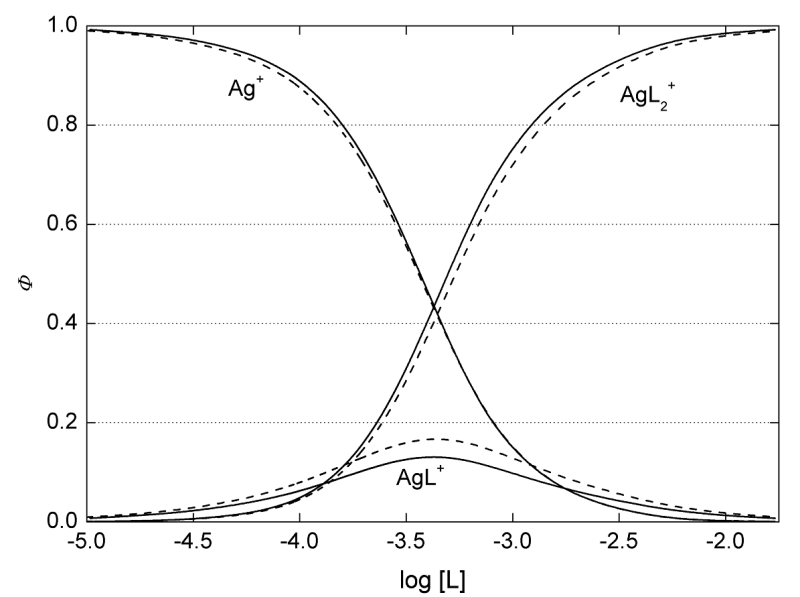

Fig. 3. Distribution diagrams for complexes of silver (I) with histidine (solid line) and imidazole (dashed line) at temperature $298.15 \mathrm{~K} ; \Phi$ - fraction of silver remaining free as $\mathrm{Ag}^{+}$or complexed as $\mathrm{AgL}^{+}$and $\mathrm{AgL}_{2}^{+},[\mathrm{L}]$ - concentration of free ligands.

ported in [8] gave the cumulative stability constant of silver + histidine very close to that determined calorimetrically (Table I). However, the calorimetric experiment gives only a rough picture of the complexation equlibria in this system. The molecule of histidine has three protonation spots (Fig. 1). Thus, the symbol L in Eqs. (1) and (2) denotes a set of chemical entities - the molecules of histidine with various numbers of protons - rather than strictly defined molecule. As a result of joining the silver ion, the equilibrium constants between protonated and deprotonated forms of the histidine molecule may change. This would explain the divergent results of the $\mathrm{pH}$-metric experiments. 


\section{References}

[1] L.D. Pettit, K.J. Powell, Stability Constants Database (SC-Database), IUPAC and Academic Software, 1993-2001.

[2] S. Sjöberg, Pure Appl. Chem. 69, 1549 (1997).

[3] J. Bauman, J. Wang, Inorg. Chem. 3, 368 (1964).

[4] R.M. Izatt, R.E. Terry, B.L. Haymore, L.D. Hansen, N.K. Dalley, A.G. Avondet, J.J. Christensen, J. Am. Chem. Soc. 98, 7260 (1976).

[5] Y. Liu, J.M. Sturtevant, Protein Sci. 4, 2559 (1995).

[6] L.E. Briggner, I. Wadsö, J. Biochem. Biophys. Methods 22, 101 (1991).

[7] S. Datta, A. Grzybowski, J. Chem. Soc. A , 1059 (1966).

[8] S. Valladas-Dubois, Bull. Soc. Chim. Fr. , 831 (1954).

[9] E.V. Legler, V.Y. Kazbanov, A.S. Kazachenko, Zh. Neorg. Khim. 47, 158 (2002).

[10] I. Smith, Diss. Kansas State Univ., 1961, cited in Ref. [1].

[11] V. Poddymov, A. Ustinova, Zh. Neorg. Khim. 26, 1307 (1981).

[12] A.E. Martell, R.J. Motekaitis, Determination and Use of Stability Constants, 2nd ed., VCH Publ., New York 1992. 